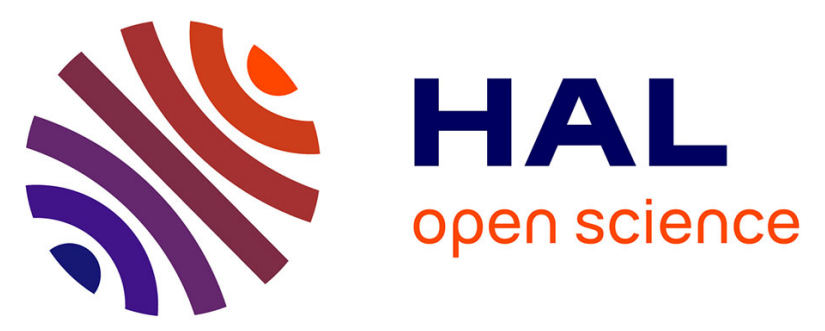

\title{
When to stop pushing: effects of duration of second-stage expulsion efforts on maternal and neonatal outcomes in nulliparous women with epidural analgesia.
}

Camille Le Ray, François Audibert, François Goffinet, William Fraser

\section{- To cite this version:}

Camille Le Ray, François Audibert, François Goffinet, William Fraser. When to stop pushing: effects of duration of second-stage expulsion efforts on maternal and neonatal outcomes in nulliparous women with epidural analgesia.. American Journal of Obstetrics and Gynecology, 2009, 201 (4), pp.361.e1-7. 10.1016/j.ajog.2009.08.002 . inserm-00460104

\section{HAL Id: inserm-00460104 https://www.hal.inserm.fr/inserm-00460104}

Submitted on 26 Feb 2010

HAL is a multi-disciplinary open access archive for the deposit and dissemination of scientific research documents, whether they are published or not. The documents may come from teaching and research institutions in France or abroad, or from public or private research centers.
L'archive ouverte pluridisciplinaire HAL, est destinée au dépôt et à la diffusion de documents scientifiques de niveau recherche, publiés ou non, émanant des établissements d'enseignement et de recherche français ou étrangers, des laboratoires publics ou privés. 


\section{When to stop pushing? Consequences of active second stage duration on maternal and neonatal outcomes in nullipara with epidural}

Camille Le Ray $(1,2,3)$ (MD, MSc), François Audibert (1) (MD, MSc), François Goffinet $(2,3)(M D, P h D)$, William Fraser (1) (MD, MSc)

(1) Sainte Justine Hospital, Department of Obstetrics and Gynecology, University of Montréal, QC, Canada

(2) INSERM UMR S149, Epidemiological Research Unit on Perinatal Health and Women's Health, F-75014, Paris, France

(3) Maternité Port Royal, Hôpital Cochin Saint-Vincent-de-Paul, Assistance Publique Hôpitaux de Paris, Université Paris-Descartes, France

Corresponding author:

Camille LE RAY, MD, MSc

INSERM Unit 149, Epidemiological Research Unit on Perinatal Health and Women's Health 82 Avenue Denfert-Rochereau

75014 Paris, France

Tel: 33142345570 / 33142345580

Fax: 33143268979

Email: camille.leray@gmail.com

This research was presented at the SMFM $29^{\text {th }}$ Annual Meeting, San Diego, CA, January $26-31,2009$

Support for the trial which generated the database for this study was from the Canadian Institutes of Health Research (CIHR) (Medical Research Council of Canada). Dr. Le Ray 
received a grant from the French National College of Obstetricians and Gynecologists (CNGOF). Dr. Fraser receives salary support through a Canada Research Chair Award. Dr. Audibert receives salary support through a CIHR New Investigator Award.

\section{Word count:}

- abstract: 153

- text: 2807 


\section{CONDENSATION}

Relative to the first hour of expulsive efforts, chances of spontaneous vaginal delivery decrease every hour, while maternal risks increase. 


\section{ABSTRACT}

Objective: To assess the influence of the duration of active second stage on maternal and neonatal outcomes.

Study design: Secondary analysis of the PEOPLE trial including 1862 second stage nulliparous women with epidural. According to duration of active second stage, we estimated the proportion of spontaneous vaginal deliveries (SVD) with a newborn without signs of asphyxia (5 minutes Apgar score $\geq 7$ and arterial $\mathrm{pH}>7.10$ ). We also analyzed maternal and neonatal outcomes according to duration of expulsive efforts.

Results: Relative to the first hour of expulsive efforts, the chances of a SVD of a newborn without signs of asphyxia decreased significantly every hour (1-2h:adjusted $\mathrm{OR}=0.4[0.3-0.6], 2-3 \mathrm{~h}$ :adjusted $\mathrm{OR}=0.1[0.09-0.2],>3 \mathrm{~h}$ :adjusted $\mathrm{OR}=0.03[0.02-0.05])$. The risk of postpartum hemorrhage and intrapartum fever increased significantly after $2 \mathrm{~h}$ of pushing.

Conclusion: Faced with a decreasing probability of SVD and increased maternal risk of morbidity after 2 hours, we raise the question as to whether expulsive efforts should be continued after this time.

Key words: duration of active second stage; nullipara; maternal complications 


\section{INTRODUCTION}

The second stage commences at full dilatation and is divided into two phases: the passive second stage when the fetal head progresses passively in the maternal pelvis and the active second stage which corresponds to the phase of active expulsive efforts. Prolonged second stage (more than 2 or 3 hours according to the authors) is associated with an increased risk of maternal complications, operative vaginal delivery, perineal trauma, chorioamnionitis, postpartum hemorrhage, but not with an increased risk of adverse neonatal outcomes (1-7). However, in most studies related to prolonged second stage, passive and active second stages were not differentiated. Because the point of onset of the $2^{\text {nd }}$ stage is difficult to determine, especially when the vaginal examinations during labor are less frequent, a measurement bias in these studies cannot be excluded (8). Conversely, the time of commencing expulsive efforts is usually accurately documented. As regards the management of the second stage, no previous cohort study has specifically analyzed maternal and neonatal outcome indicators as a function of the duration of the active phase of the second stage of labor.

Several trials have been published about the management of the second stage as regards a policy of immediate or delayed pushing, with controversial results. The PEOPLE trial (Pushing Early Or Pushing Late with Epidural) is one such trial (9). A meta-analysis of these trials found a decreased risk of rotational or mid-pelvic instrumental deliveries in the delayed pushing group, but non significant reductions of instrumental deliveries, caesarean section and adverse neonatal outcomes (10). The authors of that metaanalysis concluded that there is a benefit of delayed pushing in hospitals with high rates of rotational or mid-pelvic procedures, but no advantage in hospitals with low rates of these procedures. Thus, there are still today considerable variations in management of the second stage according to hospital protocols, obstetricians' habits and experience. 
With respect to duration of the active phase of the second stage, we hypothesized that after a certain duration of pushing, maternal and neonatal risks may outweigh the benefits of continued pushing.

The purpose of our study was to evaluate the rate of spontaneous vaginal delivery with a newborn without signs of asphyxia according to the duration of the active second stage. We also assessed the influence of the duration of active second stage on maternal and neonatal outcomes, to try to determine a "maximal" duration of pushing efforts, adjusting for the second stage management, delayed or immediate pushing. 


\section{MATERIALS \& METHODS}

We conducted a secondary analysis of all patients $(n=1862)$ included in the PEOPLE trial, a multicenter randomized controlled trial comparing early and delayed pushing with epidural, between October 1994, and September 1996, in 12 academic centers (10 in Canada, 1 in the United States, and 1 in Switzerland). Nulliparous women at term ( $\geq 37$ weeks) with a singleton vertex fetus were eligible and randomized at the beginning of the second stage. Exclusion criteria were abnormal fetal heart rate monitoring during the first stage, maternal fever during the first stage of labor, adverse events during the pregnancy (hypertension, hemorrhage, fetal malformation, intra uterine growth retardation) and any condition that necessitated shortening of the second stage of labor (9). The clinical trial was approved by the Ethics Committee of Laval University.

The management of the passive phase of the second stage was standardized. In the early pushing group, women were encouraged to commence pushing immediately on random assignment. In the late pushing group, women were advised to avoid voluntary expulsive efforts for 2 hours unless they felt an irresistible urge to push, the fetal head was visualized at the inspection of the perineum or a medical indication to shorten the second stage of labor developed. However, there was no standardized management with respect to pushing technique. For women without oxytocin during the first stage, if labor had not progressed within 1 hour after random assignment, oxytocin could be commenced. For women with oxytocin during the first stage, it was continued during the second stage of labor unless there was an indication to stop the infusion. Fetal status was assessed by continuous electronic heart rate monitoring. Continuous-infusion epidural analgesia followed a standardized protocol.

Duration of the expulsive efforts was prospectively collected and available for all with the exception of 4 patients. We categorized the duration of the active phase of the second 
stage into four classes: less than 1 hour $(h)$, interval $1-2 h$, interval $2-3 h$ and more than 3 hours.

The primary outcome was defined as a spontaneous vaginal delivery of a newborn without signs of asphyxia, i.e. Apgar score at 5 minutes $\geq 7$ and neonatal arterial $\mathrm{pH}$ $>7.10$ when available. Thus, indications of operative deliveries were taken into account. Indeed, with adequate fetal per partum surveillance, women with abnormal fetal heart rate monitoring had earlier operative delivery allowing birth of a newborn without signs of asphyxia, in comparison with women with a normal fetal heart rate.

The secondary maternal outcomes were intrapartum fever, third- and fourth- degree perineal tears and postpartum hemorrhage ( $\mathrm{PPH}$ ) defined as blood losses greater than $500 \mathrm{cc}$ with vaginal delivery and greater than $1000 \mathrm{cc}$ with cesarean section. The secondary neonatal outcomes were 5 minute Apgar score less than 7, neonatal arterial $\mathrm{pH}$ less than 7.10, any neonatal trauma (cephalhematoma, other hematoma, fracture and facial or brachial palsy) and admission to neonatal intensive care unit (NICU).

First, we described the maternal and neonatal baseline characteristics and obstetrical practices in our population. Second, according to the duration of the active phase of the second stage, we determined the rate of spontaneous vaginal delivery with a newborn without sign of asphyxia in each group of randomization (immediate or delayed pushing groups). Finally, we conducted univariable and multivariable analysis to assess the association between duration of expulsive efforts and adverse maternal or neonatal outcomes.

Statistical analysis was performed using Stata 10.0 software (Stata Corporation, College Station, TX). We used the Chi-square test to compare proportions, and Fisher's exact test when the population size was small $(n<5)$. To compare continuous variables, we used ANOVA, the variances were assessed by the Bartlett's test. 
For multivariable analysis, we used unconditional logistic regression models to adjust for confounding. Adjusted analysis controlled for maternal age (continuous), gestational age (continuous), ethnic origin (categorical), BMI at admission (continuous), birth weight (continuous), position of the fetal head at full dilatation (categorical), group of randomization (binary: early or late pushing group) and mode of delivery (categorical). For analysis of third- and fourth-degree tear, we also adjusted on episiotomy and its technique (categorical: none, median or mediolateral episiotomy). Goodness-of-fit was examined using the Hosmer-Lemeshow test. 


\section{RESULTS}

Maternal and neonatal characteristics are summarized in Table 1. Median duration of pushing efforts was 68 minutes $\left(10^{\text {th }}\right.$ percentile: $17 \mathrm{~min}$ and $90^{\text {th }}$ percentile: $175 \mathrm{~min}$ ) in the delayed pushing group and 110 minutes $\left(10^{\text {th }}\right.$ percentile: $37 \mathrm{~min}$ and $90^{\text {th }}$ percentile: $228 \mathrm{~min}$ ) in the immediate pushing group. Six hundred and thirty five (34.2\%) women pushed less than 1 hour, 605 (32.6\%) between 1 and 2 hours, 374 (20.1\%) between 2 and 3 hours and $244(13.1 \%)$ had an active second stage longer than 3 hours.

The 5 minute Apgar score was available in 1857 cases (99.7\%), but neonatal arterial pH was missing in $376(20.2 \%)$ observations. As shown on Figure 1, after the first hour of expulsive efforts, the probability of spontaneous delivery of a baby that has no indicators of asphyxia decreased with time of pushing. Among women undelivered after 2 hours of active pushing, the chances of a spontaneous vaginal delivery of a newborn without signs of asphyxia were $22.7 \%$ and $19.6 \%$ in the immediate and delayed pushing groups, respectively. After 3 hours, it decreased to $10.7 \%$ and $8.9 \%$. Using multivariable analysis, we found a significantly decreased chance for each subsequent hour to have a spontaneous vaginal delivery with newborn without signs of asphyxia (interval 1-2h: adjusted $\mathrm{OR}=0.4,95 \% \mathrm{IC}[0.3-0.6]$, interval 2-3h: adjusted $\mathrm{OR}=0.1,95 \% \mathrm{IC}[0.09-0.2]$ and pushing $>3 \mathrm{~h}$ : adjusted $\mathrm{OR}=0.03,95 \% \mathrm{IC}[0.02-0.1]$, reference: pushing $<1 \mathrm{~h}$ ) $($ Table $3)$.

Univariable analysis indicated that the proportion of maternal morbidity indicators increased significantly with duration of the active second stage (table 2). Among women undelivered after 2 hours of active pushing, the rate of post partum hemorrhage was $23.6 \%$ and it increased to $30.5 \%$ after 3 hours of pushing. The risk of operative delivery - instrumental extraction or cesarean section - was two-fold increased for interval 1-2h in comparison to those with duration of pushing less than one hour, ninefold increased for interval 2-3h and thirtyfold increased for pushing greater than 3 hours. After 
adjustment, the risk of postpartum hemorrhage increased after $2 \mathrm{~h}$ of pushing (interval 23h: adjusted $\mathrm{OR}=1.6,95 \% \mathrm{IC}[1.0-2.5]$ and pushing $>3 \mathrm{~h}$ : adjusted $\mathrm{OR}=2.5,95 \% \mathrm{IC}[1.5-$ 4.1], reference: pushing $<1 \mathrm{~h})$. The risk of intrapartum fever was also significantly associated with duration of the active second stage. In the multivariable analysis, the risks of third- and fourth-degree tears were comparable for all classes of duration of the active second stage (table 3 ).

In this context of continuous intrapartum surveillance, neonatal arterial $\mathrm{pH}$ and 5 minutes Apgar score were not influenced by pushing duration (table 2). Neonatal trauma and admission in NICU increased with duration of the active second stage in univariable analysis. After adjustment for confounding variables, none of the adverse neonatal outcomes studied were significantly associated with pushing duration (table 3 ). 


\section{COMMENT}

During the active phase of the second stage, the probability of spontaneous vaginal delivery of a newborn with a 5 minute Apgar score $\geq 7$ and $\mathrm{pH}$ at birth $>7.10$, decreases every hour. After 2 hours of pushing the risk of intra partum fever and postpartum hemorrhage increases significantly. However, our results suggest that in the context of continuous fetal surveillance in the second stage a prolonged duration of the active second stage does not increase the risk of adverse neonatal outcome.

There are few previous publications specifically addressing the impact of the duration of expulsive efforts on the fetal and neonatal well-being (11-14). These studies had a small sample size and were focused on biological outcomes ( $\mathrm{pH}$ and lactates). In our study, the population is large, homogenous (uncomplicated nulliparous women at term with epidural) and is derived from a multicenter trial cohort. The collection of data was prospective and rigorous, especially with respect to hours of pushing with only 4 subjects missing data. We classified pushing duration into four classes, and we demonstrated an increased risk for intrapartum fever and postpartum hemorrhage. In previous studies on this topic, some authors have oversimplified categorization of second stage $(<2 \mathrm{~h}$ and $>2 \mathrm{~h})$, which limits interpretation of their results $(1,4,5,7)$. Neonatal outcomes were also prospectively collected in order to analyze accurately the neonatal health status. This reinforces the validity of our results.

Previous studies concerning prolonged second stage did not differentiate passive and active phases, thus we cannot compare our results to those from other studies (1-7). However, in accordance with these studies, after adjustment, we did not find an association between duration of pushing and adverse neonatal outcomes.

In 1973, Wood showed, among 29 patients, that neonatal arterial pH decreased to 0.003 unit every minute of pushing (11). Other authors found similar results in small biological 
studies $(12,14)$. In our study with a large sample size, where there was routine fetal intrapartum surveillance using fetal heart monitoring, we found no correlation between neonatal arterial $\mathrm{pH}$ values and duration of expulsive efforts. Moreover, we found a surprising, but non significant, decrease in the rate of arterial $\mathrm{pH}$ less than 7.10 after 2 hours of pushing. This result may reflect a « healthy worker » effect, i.e. that the most fragile infants were probably born during the first 2 hours of pushing, if needed, by instrumental vaginal delivery or by cesarean section. But this result may also reflect a context of careful obstetrical management and an adequate fetal surveillance during the active second stage, performing an operative delivery when severe fetal heart rate abnormalities occured. Only women with normal fetal heart monitoring, were allowed to continue pushing after 2 hours.

Because this was a secondary analysis of a randomized trial not specifically designed to answer the study question, our study has several limitations. We had only short-term data concerning maternal morbidity indicators. The effect of prolonged expulsive efforts on pelvic floor and continence was not assessed. Moreover, data were collected in 19941996. Probably, obstetrical practices have changed since this period - fewer midpelvic extractions, fewer rotational procedures and more caesarean sections during the second stage. The operative vaginal delivery rate is high in this trial, like in other trials comparing delayed and immediate pushing (10). Thus, a selection bias cannot be excluded. In our population, most women were Caucasian or Asian. In light of the different prevalence of pelvic configurations in different ethnic groups, our results might not be generalized to ethnic groups that were under-represented in our study. Moreover, our results cannot be generalized to multipara and nullipara without epidural. Finally, because the exact duration of the first stage is difficult to estimate accurately, we did not adjust for it. First stage duration might have an influence on maternal and neonatal outcomes. 
Sung et al. found that a second stage of labor longer than 4 hours was associated with an increase in unintentional hysterotomy extensions at cesarean delivery and prolonged operative time (15). In the PEOPLE trial, there is no data about adverse events occurring during caesarean such as hysterotomy extension or bladder injury. These complications may be more frequent in case of cesarean section after 2 or 3 hours of pushing efforts as compared to cesareans performed during the first two hours of active second stage.

In 1989, Fusi was the first to describe an association between maternal pyrexia and the use of epidural in labor (16). Other authors found similar results (17). However, the exact influence of epidural on thermoregulation is still controversial (18). In our population of nullipara with epidural, there was a significantly increased risk of maternal intrapartum fever associated with pushing duration. We cannot determine if this result is due to patent infection or unbalanced thermoregulation.

Analysis of risk factors associated with a prolonged active second stage could lead to the identification of measures to decrease the duration of expulsive efforts and the associated maternal morbidity. In particular, fetal malposition at full dilatation results in a higher risk of prolonged second stage (19). In contrast to other risk factors such as fetal weight, fetal malposition can be modified using simple obstetrical maneuvers. The routine assessment of fetal head position at full dilatation before pushing is initiated and the use of manual rotation might reduce the duration of pushing and the rate of cesarean $(20-22)$

In our logistic regression analysis, we assessed whether the association between the risk of PPH and the duration of pushing was potentially mediated by the mode of delivery. Cesarean section is associated with both duration of pushing and risk of post-partum hemorrhage. The adjusted OR for PPH was significantly less than the crude OR, and the confidence interval for the effect excluded the null effect only when the duration of pushing was greater than 3 hours. It remains possible that prolonged pushing is 
associated with technically difficult cesarean sections, where the risk of hysterotomy extension is increased. Thus, cesarean would be on the chain of causality between pushing duration and $\mathrm{PPH}$.

Post partum hemorrhage is well known to be a common cause of maternal mortality morbidity. Considering that the risk of $\mathrm{PPH}$ increases significantly after 2 hours of expulsive efforts and the chance to have a spontaneous vaginal delivery of a newborn without signs of asphyxia is $20 \%$ after this time, in our study, it is justified to ask the question as to whether operative delivery - instrumental delivery or cesarean - should be considered after 2 hours pushing. However, our study did not allow us to assess whether maternal morbidity would have been reduced if an operative delivery had been systematically performed after 2 hours of pushing. A policy of assisted delivery or cesarean after 2 hours of pushing could decrease the risk of PPH associated with uterine atony and difficult cesareans. But such a policy could also increase the risk of PPH due to an increased rate of cesarean section and instrumental delivery. Our study does not provide a definitive answer to that question, but does provide additional information to assist physician in patient's counseling in such situations. Our study revives the age- old debate as to the appropriate criteria for defining an 'adequate', or for that matter, a 'failed' trial of labor - the ultimate diagnostic conundrum in obstetrics. This unresolved challenge applies both to the first and to the second stage of labor. Only a well-designed randomized controlled trial comparing neonatal and maternal outcomes between 1) a policy of limiting pushing to 2 hours and 2) a policy of no fixed limit on the duration of the active second stage, will answer the question 'when to stop pushing ?'. 


\section{REFERENCES}

1. Myles TD, Santolaya J. Maternal and neonatal outcomes in patients with a prolonged second stage of labor. Obstet Gynecol 2003;102(1):52-8.

2. Menticoglou SM, Manning F, Harman C, Morrison I. Perinatal outcome in relation to second-stage duration. Am J Obstet Gynecol 1995;173(3 Pt 1):906-12.

3. Cheng YW, Hopkins LM, Caughey AB. How long is too long: Does a prolonged second stage of labor in nulliparous women affect maternal and neonatal outcomes? Am J Obstet Gynecol 2004;191(3):933-8.

4. Janni W, Schiessl B, Peschers U, Huber S, Strobl B, Hantschmann P, et al. The prognostic impact of a prolonged second stage of labor on maternal and fetal outcome. Acta Obstet Gynecol Scand 2002;81(3):214-21.

5. Moon JM, Smith CV, Rayburn WF. Perinatal outcome after a prolonged second stage of labor. J Reprod Med 1990;35(3):229-31.

6. Saunders NS, Paterson CM, Wadsworth J. Neonatal and maternal morbidity in relation to the length of the second stage of labour. $\mathrm{Br} \mathrm{J}$ Obstet Gynaecol $1992 ; 99(5): 381-5$

7. Kuo YC, Chen CP, Wang KG. Factors influencing the prolonged second stage and the effects on perinatal and maternal outcomes. J Obstet Gynaecol Res 1996;22(3):2537.

8. Altman MR, Lydon-Rochelle MT. Prolonged second stage of labor and risk of adverse maternal and perinatal outcomes: a systematic review. Birth 2006;33(4):31522.

9. Fraser WD, Marcoux S, Krauss I, Douglas J, Goulet C, Boulvain M. Multicenter, randomized, controlled trial of delayed pushing for nulliparous women in the second stage of labor with continuous epidural analgesia. The PEOPLE (Pushing Early or Pushing Late with Epidural) Study Group. Am J Obstet Gynecol 2000;182(5):1165-72. 
10. Roberts CL, Torvaldsen S, Cameron CA, Olive E. Delayed versus early pushing in women with epidural analgesia: a systematic review and meta-analysis. Bjog $2004 ; 111(12): 1333-40$.

11. Wood $\mathrm{C}, \mathrm{Ng} \mathrm{KH}$, Hounslow D, Benning H. Time--an important variable in normal delivery. J Obstet Gynaecol Br Commonw 1973;80(4):295-300.

12. Katz M, Lunenfeld E, Meizner I, Bashan N, Gross J. The effect of the duration of the second stage of labour on the acid-base state of the fetus. $\mathrm{Br}$ J Obstet Gynaecol $1987 ; 94(5): 425-30$

13. Nordstrom L, Achanna S, Naka K, Arulkumaran S. Fetal and maternal lactate increase during active second stage of labour. Bjog 2001;108(3):263-8.

14. Aldrich CJ, D'Antona D, Spencer JA, Wyatt JS, Peebles DM, Delpy DT, et al. The effect of maternal pushing on fetal cerebral oxygenation and blood volume during the second stage of labour. $\mathrm{Br}$ J Obstet Gynaecol 1995;102(6):448-53.

15. Sung JF, Daniels KI, Brodzinsky L, El-Sayed YY, Caughey AB, Lyell DJ. Cesarean delivery outcomes after a prolonged second stage of labor. Am J Obstet Gynecol $2007 ; 197(3): 306$ e1-5.

16. Fusi L, Steer PJ, Maresh MJ, Beard RW. Maternal pyrexia associated with the use of epidural analgesia in labour. Lancet 1989;1(8649):1250-2.

17. Yancey MK, Zhang J, Schwarz J, Dietrich CS, 3rd, Klebanoff M. Labor epidural analgesia and intrapartum maternal hyperthermia. Obstet Gynecol 2001;98(5 Pt 1):76370.

18. Goetzl L, Rivers J, Zighelboim I, Wali A, Badell M, Suresh MS. Intrapartum epidural analgesia and maternal temperature regulation. Obstet Gynecol $2007 ; 109(3): 687-90$

19. Senecal J, Xiong X, Fraser WD. Effect of fetal position on second-stage duration and labor outcome. Obstet Gynecol 2005;105(4):763-72.

20. Shaffer BL, Cheng YW, Vargas JE, Laros RK, Jr., Caughey AB. Manual rotation of the fetal occiput: predictors of success and delivery. Am J Obstet Gynecol $2006 ; 194(5): e 7-9$ 
21. Le Ray C, Serres P, Schmitz T, Cabrol D, Goffinet F. Manual rotation in occiput posterior or transverse positions: risk factors and consequences on the cesarean delivery rate. Obstet Gynecol 2007;110(4):873-9.

22. Reichman O, Gdansky E, Latinsky B, Labi S, Samueloff A. Digital rotation from occipito-posterior to occipito-anterior decreases the need for cesarean section. Eur J Obstet Gynecol Reprod Biol 2008;136(1):25-8. 


\section{Figure Legends:}

Figure 1: Probability of spontaneous vaginal delivery and birth of a newborn without sign of asphyxia $(\mathrm{pH}>7.10$ and 5 minutes Apgar score $\geq 7)$ according to pushing duration and the randomization group among women undelivered at the beginning of the period 
Table 1: Description of the population - maternal, neonatal characteristics and obstetrical practices

\begin{tabular}{|c|c|}
\hline Characteristics & $\begin{array}{l}\text { Nullipara } \\
(\mathrm{n}=1862)\end{array}$ \\
\hline \multicolumn{2}{|l|}{ Group of randomization } \\
\hline - Late Pushing & $936(50.3 \%)$ \\
\hline - Early Pushing & $926(49.7 \%)$ \\
\hline Maternal age in years (mean+/-SD) & $28.1+/-4.9$ \\
\hline \multicolumn{2}{|l|}{ Ethnic origin } \\
\hline - Caucasian & $1616(86.9 \%)$ \\
\hline - Asian & $133(7.1 \%)$ \\
\hline - Other & $110(5.9 \%)$ \\
\hline BMI at admission (mean+/-SD) & $28.6+/-4.2$ \\
\hline Gestational age in weeks (mean+/-SD) & $39.8+/-1.2$ \\
\hline \multicolumn{2}{|l|}{ Onset of labor } \\
\hline - spontaneous & $1288(69.2 \%)$ \\
\hline - induction & $574(30.8 \%)$ \\
\hline - oxytocin & 292 \\
\hline - rupture of membranes & 156 \\
\hline - prostaglandins & 275 \\
\hline Duration of pushing efforts (mean+/-SD) & $99.8 \min +/-68.6$ \\
\hline - Late Pushing group & $81.8 \min +/-61.2$ \\
\hline - Early Pushing group & $117.9 \min +/-70.9$ \\
\hline \multicolumn{2}{|l|}{ Duration of pushing efforts } \\
\hline - Less than 1 hour & $635(34.2 \%)$ \\
\hline - Interval $1-2 \mathrm{~h}$ & $605(32.6 \%)$ \\
\hline - Interval 2-3h & $374(20.1 \%)$ \\
\hline - $\quad$ More than 3 hours & $244(13.1 \%)$ \\
\hline
\end{tabular}




\begin{tabular}{|c|c|}
\hline Position of the fetal head at full dilatation & $1198(64.3 \%)$ \\
$-\quad$ anterior & $200(10.7 \%)$ \\
$-\quad$ transverse & $210(11.3 \%)$ \\
$-\quad$ posterior & $254(13.6 \%)$ \\
\hline Mode of delivery & $1026(55.1 \%)$ \\
$-\quad$ spontaneous vaginal delivery & $736(39.5 \%)$ \\
$-\quad$ cesarean & $100(5.4 \%)$ \\
\hline Episiotomy in cases of vaginal delivery & $1095(58.8 \%)$ \\
$(\mathrm{n}=1762)$ & $459(27.7 \%)$ \\
$-\quad$ none & $308(16.5 \%)$ \\
\hline - median & $3469+/-421$ \\
\hline Birth weight in grams (mean+/-SD) & \\
\hline
\end{tabular}

* forceps, vacuum, manual or instrumental rotation 
Table 2: Maternal and neonatal morbidity indicators according to each pushing duration category

\begin{tabular}{|l|c|c|c|c|c|}
\hline & $\begin{array}{c}<1 \text { hour } \\
(\mathrm{n}=635)\end{array}$ & $\begin{array}{c}1-2 \text { hours } \\
(\mathrm{n}=605)\end{array}$ & $\begin{array}{c}2-3 \text { hours } \\
(\mathrm{n}=374)\end{array}$ & $\begin{array}{c}>3 \text { hours } \\
(\mathrm{n}=244)\end{array}$ & $\mathrm{p}^{*}$ \\
\hline Post partum & $53(8.4 \%)$ & $75(12.7 \%)$ & $70(19.5 \%)$ & $64(31.1 \%)$ & $<0.001$ \\
\hline hemorrhage & & & & & \\
\hline perineal tear & $98(6.0 \%)$ & $47(7.8 \%)$ & $52(13.9 \%)$ & $38(15.7 \%)$ & $<0.001$ \\
\hline Intrapartum fever & $21(3.3 \%)$ & $38(6.3 \%)$ & $33(8.8 \%)$ & $30(12.3 \%)$ & $<0.001$ \\
\hline Arterial pH (mean & $7.25+/-$ & $7.24+/-$ & $7.25+/-$ & $7.26+/-$ & 0.009 \\
$+/-S D)$ & 0.07 & 0.087 & 0.07 & 0.07 & 0.020 \\
\hline Arterial pH $\leq 7.10$ & $18(3.6 \%)$ & $25(5.2 \%)$ & $5(1.7 \%)$ & $3(1.4 \%)$ & 0.566 \\
\hline 5 min Apgar score $<7$ & $5(0.8 \%)$ & $8(1.3 \%)$ & $3(0.8 \%)$ & $4(1.6 \%)$ & 0.004 \\
\hline Neonatal trauma & $34(5.4 \%)$ & $41(6.8 \%)$ & $42(11.2 \%)$ & $30(12.3 \%)$ & $<0.001$ \\
\hline Admission in NICU & $22(3.5 \%)$ & $25(4.1 \%)$ & $26(7.0 \%)$ & $21(8.6 \%)$ & 0.004 \\
\hline
\end{tabular}

*chi-square test with 3 degrees of freedom

NICU: neonatal intensive care unit 
Table 3: Maternal and neonatal outcomes according to pushing duration.

Univariable and multivariable analysis, using logistic regression models

\begin{tabular}{|c|c|c|c|c|c|c|}
\hline & \multicolumn{2}{|c|}{ 1-2 hours } & \multicolumn{2}{|c|}{ 2-3 hours } & \multicolumn{2}{|c|}{$>3$ hours } \\
\hline & Crude OR 95\%IC & Adjusted OR 95\%IC $\neq$ & Crude OR 95\%IC & Adjusted OR 95\%IC $\neq$ & Crude OR 95\%IC & Adjusted OR 95\%IC $\neq$ \\
\hline $\begin{array}{l}\text { Primary outcome: Spontaneous } \\
\text { vaginal delivery of a newborn } \\
\text { without sign of asphyxia }\end{array}$ & $0.4[0.3-0.6]$ & $0.4[0.3-0.6]$ & $0.1[0.09-0.2]$ & $0.1[0.09-0.2]$ & $0.03[0.02-0.05]$ & $0.03[0.02-0.05]$ \\
\hline Operative delivery & $2.3[1.8-3.0]$ & $2.3[1.7-3.0]$ & $9.3[6.9-12.5]$ & $9.0[6.5-12.3]$ & $32.9[21.0-51.6]$ & $31.0[19.3-50.0]$ \\
\hline Post partum hemorrhage & $1.6[1.1-2.3]$ & $1.2[0.8-1.8]$ & $2.6[1.8-3.9]$ & $1.6[1.0-2.5]$ & $4.9[3.3-7.4]$ & $2.5[1.5-4.1]$ \\
\hline $3^{\text {rd }}$ and $4^{\text {th }}$ degree perineal tear $*$ & $1.3[0.8-2.1]$ & $1.0[0.6-1.6]$ & $2.5[1.6-3.9]$ & $1.2[0.7-2.0]$ & $2.9[1.8-4.7]$ & $1.7[0.9-3.0]$ \\
\hline Intra-partum fever & $2.0[1.1-3.4]$ & $1.8[1.0-3.2]$ & $2.8[1.6-5.0]$ & $2.1[1.1-4.0]$ & $4.1[2.3-7.3]$ & $2.7[1.3-5.5]$ \\
\hline 5 minutes Apgar score $<7$ & $1.7[0.5-5.2]$ & $1.1[0.3-3.6]$ & $1.0[0.2-4.3]$ & $0.4[0.1-2.1]$ & $2.1[0.6-7.9]$ & $0.7[0.1-3.5]$ \\
\hline Arterial $\mathrm{pH} \leq 7.10$ & $1.5[0.8-2.7]$ & $1.6[0.8-3.0]$ & $0.5[0.2-1.2]$ & $0.4[0.1-1.3]$ & $0.4[0.1-1.3]$ & $0.2[0.1-1.1]$ \\
\hline Neonatal trauma & $1.3[0.8-2.1]$ & $1.2[0.7-2.0]$ & $2.2[1.4-3.6]$ & $1.5[0.8-2.6]$ & $2.5[1.5-4.1]$ & $1.7[0.9-3.3]$ \\
\hline Admission in NICU & $1.2[0.7-2.2]$ & $1.1[0.6-2.0]$ & $2.1[1.2-3.7]$ & $1.5[0.8-3.0]$ & $2.6[1.5-4.9]$ & $1.5[0.7-3.3]$ \\
\hline
\end{tabular}

Reference: pushing duration $<1$ hour

ҒAdjustment on maternal age, gestational age, ethnic origin, BMI at the admission, birth weight, position of the fetal head at full dilatation, group of randomization (Early or Late Pushing), mode of delivery (excepted for the primary outcome and operative delivery)

*Adjustment also on episiotomy and its technique (median or mediolateral) 


\section{ANNEXE:}

The following is a list of participants in the PEOPLE Study Group.

Steering Committee: William D. Fraser, MD, Sylvie Marcoux, MD, PhD, Isabelle Krauss, MD, MSc, Joanne Douglas, MD, and Céline Goulet RN, PhD.

Center investigators and research assistants: J. Chabot, MD, J. Flamand, RN, L. Laperrière, BN, CHUQ-Pavillon St François d'Assise, Quebec, Quebec, Canada; P. Fish, MD, and G. Hamel, RN, Hôpital de Chicoutimi, Chicoutimi, Quebec, Canada; R. Sabbah, MD, and L. Vincelli, RN, Hôpital Sacré-Coeur de Montréal, Montreal, Quebec, Canada; G. Tawagi, MD, O. Rosag, MD, and J. Belcher, RN, Ottawa Civic Hospital, Ottawa, Ontario, Canada; F. Galerneau, MD, M. Klein, MD, J. Swenerton, MD, B. Weibe, RN, and E. Nickel, RN, BC Women's Hospital, Vancouver, British Columbia, Canada; K. Milne, MD, J. Fuller, MD, and L. Watson, RN, St Joseph's Hospital, London, Ontario, Canada; O. Irion, MD, K. Rifat, MD, and V. Mentha (midwife), Hôpitaux Universitaires de Genève, Geneva, Switzerland; S. Bottoms, MD (deceased), and B. Steffy, RN, Hutzel Hospital, Detroit, Michigan; M. Helewa, MD, S. Lucy, MD, and S. Erickson, RN, St Boniface Hospital, Winnipeg, Manitoba, Canada; N. Okun, MD, A. Guest, MD, A. Stuart, MD, and D. Schimeck, RN, University of Alberta Hospital, Edmonton, Alberta, Canada; M. Sermer, MD, and M. Bailey, RN, Toronto General Hospital, Toronto, Ontario, Canada; and D. Blouin, MD, Y. Claprood, and D. Beaulieu, RN, Center Hospitalier Universitaire de I'Estrie, Sherbrooke, Quebec, Canada.

Data Management Committee: Michel Boulvain, MD, PhD, Sylvie Bérubé, PhD, and Isabelle Faron.

Safety and Efficacy Monitoring Committee: François Meyer, MD, PhD, Aida Bairam, MD, PhD, and Jean-Marie Moutquin, MD. 